\title{
EL MUSEO-MAUSOLEO: LA BÚSQUEDA DEL PLACER A TRAVÉS DE LA COLECCIÓN DE OBJETOS ARTÍSTICOS EN EL PICADERO DE ADOLFO COUVE ${ }^{1}$
}

\section{THE MUSEUM-MAUSOLEUM: THE PURSUIT OF PLEASURE THROUGH THE COLLECTION OF ARTISTIC OBJECTS IN ADOLFO COUVE'S EL PICADERO}

\author{
Alexandra Novoa Romero \\ Universidad de Concepción, Chile \\ alexandranovoa2020@gmail.com \\ Juan D. Cid Hidalgo \\ Universidad de Concepción, Chile \\ juandcidh@gmail.com
}

\begin{abstract}
Resumen:
Este artículo tiene como objetivo leer El picadero (1974) de Adolfo Couve desde las ideas de colección, museo y mausoleo. La nouvelle manifiesta una galería de arte que exhibe los retratos-personajes, quienes se convierten en objetos de colección y al mismo tiempo coleccionadores de objetos. El deseo impetuoso y obsesivo de los personajes por poseer objetos materiales e inmateriales es debido al placer intemporal que les produce adquirir nuevas piezas, olas de felicidad que hace sus vidas menos tortuosas. De esta manera, los personajes transforman la casona de Villacler en un museo, no obstante, este termina por reducirse a un mausoleo, ya que la mayoría de los personajes fallecen.
\end{abstract}

Palabras clave: Adolfo Couve, colección, retratos-personajes, museo, mausoleo.

\begin{abstract}
:
This article aims to read El picadero (1974) by Adolfo Couve from the perspectives of the collection, the museum and the mausoleum. The nouvelle presents an art gallery under the context of a portrait-characters exhibition. These, become objects of collection and, at the same time, collectors of objects. The impulsive and obsessive desire of the characters to possess material and immaterial goods is due to timeless pleasure of getting new belongings, waves of happiness that make their lives less tortuous. In that way, the characters turn Villacler'a house into a museum, however, it ends up being reduced to a mausoleum since most of the characters die.
\end{abstract}

Keywords: Adolfo Couve, collection, character portraits, museum, mausoleum.

Recibido: 27 de septiembre de 2021

Aceptado: 22 de noviembre de 2021

\footnotetext{
${ }^{1}$ Este trabajo es producto del curso "Nuevas tendencias en las literaturas hispanoamericanas y chilena actuales" dictado por el Dr. Juan D. Cid Hidalgo en el Magíster en Literaturas Hispánicas de la Universidad de Concepción y se enmarca en el grupo de investigación Literatura y artes visuales. Sobre tránsitos, curadurías y montajes (VRID 19.F1.01) dirigido por el mismo académico.
} 
Artículo. Alexandra Novoa Romero, Juan D. Cid Hidalgo. "El museo-mausoleo: la búsqueda del placer a través de la colección de objetos artísticos en El picadero de Adolfo Couve"

El escritor, pintor y académico chileno Adolfo Couve (1944 -1998) fue un artista reconocido, aunque desatendido por su "anacronismo" formal frente a las modalidades experimentales en boga durante los años 70 y 80 en Chile. Su aparente desentendimiento del contexto histórico chileno, sumado a su ausencia de militancia política, fueron forjando una imagen marginal acrecentada por el abrupto y excéntrico hito de alejamiento de la pintura de caballete para dedicarse a la literatura. Claudia Campaña -alumna, discípula, gran difusora y amiga de nuestro autor-, recuerda que la mítica quema de lienzos la realizó a principios de los 70, en pleno gobierno de Salvador Allende:

El mismo me contó que encendió una pira cerca de su casa de calle Guardia Vieja y quemó todos los óleos que, según su opinión, no estaban bien solucionados. Se reía porque pidió a varias personas que tenían pinturas suyas que se las prestaran por un rato, para nunca más devolvérselas. Sobrevivieron muy pocos óleos fechados entre 1970 y 1974, año en que dejó de pintar (Rozas 2017)

A pesar de su sólida formación en el arte plástico, deja esta disciplina para incursionar en la escritura, donde prontamente aparecerá El picadero, obra que hoy nos ocupa y que inicia una programática propuesta literaria cuyo centro es la técnica realista en que la observación es fundamental para una escritura elaborada y precisa: "Lo correcto es que el escritor se preocupe de escribir bien y punto" (Couve 82). Tanto la pintura como la literatura, tanto el lienzo y el pincel, como el papel y la letra son modalidades o inscripciones que Couve maneja desde el registro realista, nostálgico o abstracto, para exhibir marginalidades, rostros alternos, formas de belleza no canónicas, saberes menores, historias mínimas.

El picadero nouvelle publicada en 1974 por la Editorial Universitaria, reconocimiento anterior al del público lector y una apuesta subversiva en tiempos de dictadura, es un relato que se centra, como varios otros trabajos literarios de Couve $^{2}$, en la infancia perturbadora de Angelino y su incipiente amor por el teniente Codarco, el

\footnotetext{
${ }^{2}$ El interés creciente por nuestro autor lleva -en 1996- a la editorial Seix Barral, a publicar Cuarteto de infancia, volumen que reúne cuatro textos: El picadero, El tren de cuerda, La lección de pintura y El pasaje, todos ellos conectados temáticamente por la aparición de niños o adolescentes en formación. Singularmente interesante sería trabajar con la noción Künstlerroman o novela de artista, esa variante específica de la novela de aprendizaje o de formación Bildungsroman, para evidenciar precisamente como la genialidad pareciera punible por su carácter perturbador del orden establecido.
} 
instructor de equitación. El texto se encuentra montado episódicamente, cada capítulo tiene autonomía, la estructura fragmentaria se alimenta a partir de los cambios bruscos de narrador, saltos temporales y espaciales. El destacado y polémico crítico chileno Ignacio Valente subraya, en una columna publicada en El Mercurio (27 octubre 1974), recién editada la novela:

El autor ha sido fiel a sus sombras, a sus obsesiones, a su melancolía de la vida; ha creado el montaje exacto -imperfecto y disperso como sus propias criaturas- para revelar esa dispersión existencial. "El picadero" es una novela intrépida, sin impostación de voz, sin trucos formales, artística en el mejor sentido, llena de una secreta sabiduría, de una serena tristeza, con páginas de una penetración magistral en el misterio de las relaciones humanas, en la inanidad de los destinos humanos. Su desencanto es su verdad, es su calidad literaria, es su belleza (Valente s/p)

En la narrativa de este autor tal como lo plantea Adriana Valdés (2003) "se puede ubicar el afán "realista" de Couve, esa construcción a pulso, de un objeto externo, donde se crea, también a pulso" (10). Recordamos este fragmento porque Adolfo Couve en su novela nos permite observar una galería de personajes-retratos, quienes manifiestan a través de sus acciones cómo se enfrentan a la vida. En los diferentes relatos los personajes dejan en manifiesto su decadencia, debido a que se encuentran en reiterados conflictos internos y externos, en una suerte de inadecuación existencial que los retrata como excepcionales, a pesar de su manifiesta marginalidad y representación molecular. Al respecto leemos en "Acerca de los espacios novelares marginales en La comedia del arte de Adolfo Couve" (2020) de Cid y Grandón, que:

A partir de una concepción desprejuiciada respecto de lo marginal, de la fealdad y la miseria, el autor despliega una mirada alterna en los espacios de borde en busca de la reivindicación de la miseria, a la vez que relativizar el canon estético que prestigia temas y motivos lejanos al campo de referencia de quienes habitan el borde. La exhibición de aquellos espacios, los personajes y los paisajes minoritarios, su composición plástica y narrativa, sin embargo, dialogan permanentemente con la tradición pictórica de elite (Cid y Grandón 145). 
Artículo. Alexandra Novoa Romero, Juan D. Cid Hidalgo. "El museo-mausoleo: la búsqueda del placer a través de la colección de objetos artísticos en El picadero de Adolfo Couve"

\section{Hacia el museo-mausoleo}

El/los narrador/es de Couve obligan al lector a estar en constante interrogación frente a la lectura, puesto que los personajes, quienes pertenecen a la aristocracia a excepción de Condarco y Caudillo, en sus diferentes acciones intentan salir del mundo asfixiante al que pertenecen, sin éxito. Como diría Valente, la breve novela exhibe "un puñado de vidas crepusculares, cargadas de pasado, que se disipan en un tiempo sin horizontes, son la materia de este ejercicio retrospectivo" (Valente $\mathrm{s} / \mathrm{p}$ ). De algún modo todo el proyecto Picadero constituye una colección, una exposición de retratos de los cuales dan testimonio los capítulos que llevan nombres de personas y su singular presentación ante los ojos de los lectores. La acaudalada familia se encuentra derruida por el paso del tiempo que exige convencionalismos y rituales que ponen en tensión a los personajes quienes reaccionan (como en el laboratorio realista de la novela decimonónica) frente a su rol en el mundo. Ante esta inapertura cada personaje sentirá la necesidad de llenar su vacío con una colección de objetos materiales e inmateriales.

Nuestros personajes, entonces, buscan asirse a una esperanza a algo que le dé argumentos para sostener su existencia, en palabras de Regis Debray (2001), el acto de coleccionar se puede entender como una "fábrica de visibilidad" (93). En la misma línea Philipp Blom en El coleccionista apasionado. Una historia íntima (2013) subraya los alcances de la actividad de coleccionar cuando apunta:

Durante toda la Edad Media, los príncipes de la Iglesia y los gobernantes laicos acumularon montones de reliquias, recipientes lujosos, joyas y objetos tales como cuernos de unicornio y otras criaturas legendarias. A partir de dichos tesoros se desarrolló, desde el siglo XIV, una modalidad privada de apreciación del coleccionismo, el studiolo, una habitación construida ad hoc y repleta de antigüedades, piedras preciosas y esculturas, popular en Italia entre hombres con recursos y cultura. Se cree que Oliviero Forza, de Treviso, tuvo, en 1335, el primer studiolo del que se conservan datos. Coleccionar obras de arte y objetos diseñados con metales y piedras preciosas pasó a ser un pasatiempo principesco, una diversión que podía llegar a confundirse con una pasión devoradora (Blom 30) 
Es esta pasión perturbadora la que moviliza la novela. Sus personajes construyen una especie de museo privado -en tanto son obsesivos coleccionistas de particulares objetos artísticos-, en el cual, el acto de coleccionar provoca el placer por la posesión ${ }^{3}$. Aun cuando la función placentera es reconocible, también lo es su fin: la muerte. De esta manera, la casona de Villacler se trasforma en un museo-mausoleo ${ }^{4}$.

El picadero proyecta escenarios reconocibles como nacionales y otros como extranjeros, de hecho, Villacler pareciera el ejemplo evidente de aquello, un recinto privado perteneciente a la acomodada familia de los Sousa y cuya casona se nos exhibe como un espacio hermético abandonado a su propia suerte: “Cuando me apeé en Villacler y el empleado me condujo a través de esa interminable columnata de piedra devastada por el viento, hasta los prados que en extensos desniveles invitaban a profundizar en el horizonte, comprendí que de allí no se regresaba nunca más" (Couve 58). Este parque enorme con aires de jardín renacentista se transforma en una especie de museo para todos los personajes que transitan en él -es un dispositivo de control (Castilla, 2010; Foucault, 2004; Crimp 1993; González Echevarría, 2000)-, que como bien apunta el narrador “de allí no se regresaba nunca más". El personaje que quiere instalarse, que desea pertenecer al lugar, tiene una razón poderosa para ello pues se ha encontrado y enamorado del objeto artístico más valioso de la casona, Blanca Diana. Su descripción es ejemplar:

\footnotetext{
${ }^{3}$ Alfonso Reyes en Calendario (1924) reflexiona alrededor de estos temas y sugiere liberarse y deshacerse de los objetos, idea reaccionaria cuando sabemos que el ejercicio museal, desde su origen y concepción, proyecta una profunda obsesión por ellos, lo que se materializa en un anhelo de posesión casi incontrolable. El premio nobel turco, Orhan Pamuk, en El museo de la inocencia (2008) es categórico cuando señala que la obsesión por los objetos es un indicador de la imposibilidad de poseer aquello que se desea y que en el acto de coleccionar se logra rozar el fuego del placer por la posesión (Pamuk 458).

${ }^{4}$ Theodoro Adorno en "Museo Valéry-Proust", ensayo que leemos en Prismas. La crítica de la cultura y la sociedad (1962) describe ejemplarmente la tensión entre museo y mausoleo cuando apunta: "La expresión museal tiene en alemán un aura hostil. Designa objetos respecto de los cuales es espectador no se comporta vitalmente y que están ellos mismos condenados a muerte. Se conservan más por consideración histórica que por necesidad actual. Museo y mausoleo no están sólo unidos por la asociación fonética. Museos son como tradicionales sepulturas de obras de arte, y dan testimonio de la neutralización de la cultura. Los tesoros artísticos se acumulan en ellos: el valor de mercado elimina la satisfacción del contemplar, pero, en compensación, se exhiben los museos" (Adorno 187).

${ }^{5}$ Douglas Crimp, crítico de arte, ensayista, curador, activista y académico de la Universidad de Rochester evidencia el tronco común de la reflexión sobre el museo como dispositivo de control en "Sobre las ruinas del museo" (2005), cuando apunta: "Foucault analizó las instituciones modernas de confinamiento -el manicomio, la clínica y la prisión- y sus respectivas formaciones discursivas -la locura, la enfermedad y la criminalidad-. Existe otra institución de confinamiento -el museo- y otra disciplina - la historia del arte- a la espera de un análisis arqueológico. Ambos conforman las condiciones previas para el discurso que conocemos como arte moderno. El mismo Foucault sugirió cómo empezar a pensar este análisis" (Crimp 63).
} 
Artículo. Alexandra Novoa Romero, Juan D. Cid Hidalgo. "El museo-mausoleo: la búsqueda del placer a través de la colección de objetos artísticos en El picadero de Adolfo Couve"

Era muy hermosa, con aquella pregunta que nos hacemos ante las cabezas griegas. Sin un solo detalle y provista de todos. Líneas simples y profundas que, envolviéndola entera, entregaban los más armónicos rasgos (...) el mentón, sitio de las emociones, a veces tembloroso y débil, en otras firmes y olvidado al cincel de un arcaico artesano (Couve 59)

Ante los rasgos griegos que destaca el narrador sobre la protagonista, Blanca se convierte para el lector en un ser sublime merecedor de toda admiración, en tanto sigue la focalización sugerida y la puesta en valor del deseo que proyecta la sola posibilidad de poseerla. En presencia de esta descripción que la codifica, Blanca será vinculada con una estatua "(por su nombre y palidez, en medio de una casona de campo desierta, ya la asociamos a las clásicas esculturas de Diana la Cazadora que coronan los jardines de casas aristocráticas)" (Toro 182). De este modo, este personaje-objeto que goza de valor artístico debe instalarse naturalmente en un espacio consagratorio de su belleza, es decir, en un museo, específicamente Villacler. Didi Maleuvre en Museum Memories: History, Technology, Art (1999) señala que "el museo no es sólo el lugar donde el arte es curatoriado, también es donde el arte es encarcelado (...) bloquea aquellos elementos considerados demasiado peligrosos o demasiado bellos para moverse libremente en el dominio público"6 (en Cid 2019), el carácter subversivo implícito en Blanca Diana busca ser contenido en el museo Villacler. Así pues, sucede con la protagonista y con Angelino, quienes son enclaustrados en un museo por el hecho de ser considerados deidades, gracias a sus rasgos finos de esculturas griegas y angelicales rostros, de esta manera se convierten en objetos de colección.

Asimismo, Michel Foucault se refiere al museo como una heterotopía de tiempo ${ }^{7}$, indicando que "los hombres se encuentran en una especie de ruptura absoluta con su tiempo tradicional” (Foucault s/p) ¿no sucede así con las galerías de arte, con los museos, con las colecciones? El placer por la posesión a que aludimos arriba queda de manifiesto en la rápida institucionalización o canalización del deseo, en la conformación de un dispositivo,

\footnotetext{
${ }^{6}$ Traducción del académico el Dr. Juan D. Cid Hidalgo de la Universidad de Concepción en su artículo Larco: museo, memoria, déjà vu (2019).

${ }^{7}$ Espacios otros: utopías y heterotopías. (1974) de Michel Foucault. A este propósito Sergio Albano, en su Michel Foucault. Glosario de aplicaciones (2004), destaca que "Existen primeramente heterotopías del tiempo que se acumula hasta una progresión infinita, como por ejemplo los museos y las bibliotecas. Son heterotopías donde el tiempo no cesa de acumularse sobre sí mismo, mientras que durante casi todo el siglo XVII, los museos y las bibliotecas eran la expresión de una selección individual”. (Albano 75).
} 
de un archivo que da cuenta de aquello que perturba el orden habitual. El museo en estas coordenadas se puede entender como:

la idea de constituir una especie de archivo general, la voluntad de encerrar en un lugar todos los tiempos, todas las épocas, todas las formas, todos los gustos, la idea de constituir un lugar de todos los tiempos que esté fuera del tiempo, e inaccesible a su mordida, el proyecto de organizar así una suerte de acumulación perpetua e indefinida del tiempo en un lugar inamovible... (Foucault s/p)

Es decir, el museo se convertiría en un espacio de acumulación del tiempo, como sucede con la fotografía del efebo Angelino después de fallecer, por ejemplo ${ }^{8}$. En la nouvelle de Adolfo Couve se puede observar que la existencia del museo tiene que ver con el interés del coleccionista por poseer objetos artísticos, que pueden ser materiales tales como: cuadros, porcelanas, pañuelos de seda, etc.; o también inmateriales como el amor. Esto quiere decir, que no cualquier objeto puede ser considerado parte de una colección, no todos pueden incorporarse o pertenecer al "mundo museal" ya que el proceso de selección de aquello valioso necesariamente significa el desprecio de otro elemento. El acto curatorial entonces es interesado, discriminador y censor en la medida en que tiene una intencionalidad que se registra a nivel del montaje de la colección, la confección de un guion museográfico, el despliegue de una concepción orgánica de los componentes de la muestra exhibida, la puesta en valor de los objetos, el trazado de una visibilidad alterna y la confección de un discurso metaestético que pugna por un prestigio equivalente al de la obra. El acto de coleccionar, en tanto, no deja de ser una actividad atávica elemental de aprecio, en algunos casos intuitivo, de aquella obsesión o seducción sentida por los objetos (Blom 2013) que se nos aparecen, como dirá Aurora León, como un instrumento "visual" de la ideología (León 32-48) o de la clase dominante.

En la casona-museo existen dos "objetos" invaluables, en otras palabras, dos sujetos cosificados a tal punto de convertirse en archivos: la protagonista Blanca Diana y Angelino

\footnotetext{
${ }^{8}$ Por otro lado, Desvallées y Mairesse en su Conceptos de museología (2010) indican que el museo "puede designar tanto a la institución como al establecimiento o lugar generalmente concebido para proceder a la selección, el estudio y la presentación de testimonios materiales e inmateriales del individuo y su medio ambiente" (52), por lo tanto, las implicancias de lo museal en literatura tienen enormes posibilidades de estudio. Por ello recomendamos: Archivo y novela. Sobre la dimensión museal de la literatura latinoamericana (2017) y Museo, novela, archivo. Aproximación a los museos de papel (2017), ambos textos del académico Juan D. Cid Hidalgo.
} 
Artículo. Alexandra Novoa Romero, Juan D. Cid Hidalgo. "El museo-mausoleo: la búsqueda del placer a través de la colección de objetos artísticos en El picadero de Adolfo Couve"

su hijo, quienes son descritos como ornamentos, como parte del decorado, como evidencia del esplendor pasado. Puntualmente, Angelino siempre fue atesorado como un adorno o decorado de la casa, sin embargo, la muerte no vino sino a mitificar e inmortalizarlo: "El cuerpo del joven estaba intacto, la corrupción no lo alcanzó. Es lo que más pueden esperar los santos de las bondades de este mundo" (Couve 74). Percibimos en esta descripción una especie de sublimación del personaje, que posterior a su muerte es considerado un ángel y que, además, ha pasado al umbral de los recuerdos, puesto que la fotografía del efebo estaba en una de las tantas habitaciones-galerías de la casona: "Su fotografía (relegada más tarde al cuarto de alojados) se hizo cada vez más intratable. La verdad es que rejuveneció entre nuestras vejeces, permaneciendo en ese sepia que lo rodeo de luces inocentes" (Couve 73). De esta manera, la sublimación tanto de la protagonista como de Angelino los reviste de un estatus distinto, un estatus museable, es decir, con la dignidad suficiente como para formar parte de una colección original resguardada en los límites de la casona de Villacler.

Al igual que toda institución museal decimonónica la casona Villacler tenía otra funcionalidad en su origen, es decir, se encontraba alejada de la posibilidad de erigirse como un espacio sacralizado. En principio la casona manifestaba el paso del tiempo y el deterioro de la clase, Villacler es descrito como un espacio poco cuidado donde el tiempo ha dejado su inscripción e inmovilidad:

nuestra casa tiene muchos, muchos años, y el parque otros tanto, entonces nunca nos sentiremos en lo propio. Ni la misma Blanca se atrevió a cambiar la disposición de los muebles en Villacler (...) esos pesados muebles y sus sombras hacían un todo junto a los muros (Couve 68)

En este espacio, en que el paso del tiempo parece inmovilizar su contenido, también percibimos que se exhibe la decadencia de Villacler, que, sin embargo, muta o se transforma en un espacio museal, un "lugar de memoria" (Nora 2009) que conserva a la vez que pone en valor aquello que se ubica dentro de sus coordenadas. Los muebles, las alfombras y la decoración se halla intacta, como el cuadro de Zapiola (padre del señor Sousa) pintado al óleo. "Allí en el comedor habían colgado su retrato. Sobre la armadura que despedía fulgurantes rayos metálicos, caían armoniosos bucles de su peluca" (Couve 68). El cuadro será también parte de esta galería, puesto que Zapiola es presentado como un antepasado ilustre, digno de recordar y actualizar en la memoria familiar. 
El esposo de Blanca Diana es un coleccionista de bagatelas que evidencian ese snobismo de clase acomodada que reúne colecciones a partir de viajes que los distinguen del común de las gentes:

Después del nacimiento de Angelino, se dedicó a viajar y no volver, pretextando interesarse por completar sus colecciones de cuadros en las galerías de Europa. Allí envuelto en una bandera, cantaba la canción nacional a los pintores en sus talleres. Compró la más fabulosa colección de falsificaciones, papeles barnizados y pastiches que uno puede imaginar (Couve 99)

El señor Sousa heredó grandes riquezas de su padre, por lo tanto, su situación financiera no daba para preocupaciones; sin la necesidades de trabajar o sustentar el hogar, dispone de tiempo y dinero para visitar galerías, anticuarios y museos, de esta modo, se fue creando una imagen culta e intelectual del personaje, aun cuando "La mayoría de aquellos cuadros del siglo dieciséis y el diecisiete eran falsificaciones muy bien realizadas" (Couve 102), logrando dar cuerpo a una pinacoteca con obras de arte originales y falsas. La curaduría de esta colección tiene una impronta situada en los énfasis e intencionalidad de aquel que escoge, selecciona, monta y justifica la exhibición.

La creación de un museo o la formación de una colección lleva implícito un proceso de descolocación y de reencuentro de las obras en un orden diferente creado por el coleccionista, generando una nueva comunicación con las demás piezas, relación que nada tendrá que ver con la que tuvo en su contexto de procedencia (Antigüedad del Castillo-Olivares 14)

El señor Sousa, en cuanto coleccionista confeso, busca otorgar valor a aquellos archivos falsificados, menores y de dudosa calidad, en la medida en que el contexto material de su exhibición esté revestido de preocupación por los detalles, técnicos si se quiere (características de la sala, luz, color, etc.), para dar soporte a reproducciones e imitaciones que de otro modo no tendrían ningún valor más allá del aprecio familiar por el coleccionista. Sousa crea esta galería dentro de su hogar, un espacio privado donde cada objeto de la colección asume un lugar significativo en esa especie de relato construido a partir del guion museal que define la exhibición. La adecuación de los espacios de la 
Artículo. Alexandra Novoa Romero, Juan D. Cid Hidalgo. "El museo-mausoleo: la búsqueda del placer a través de la colección de objetos artísticos en El picadero de Adolfo Couve"

casona, entonces, buscan elevar el valor de aquello contenido en la sala de museo, de modo que el recinto museal sacralice los objetos en su interior.

Instalar esa luz cenital que iluminaba las hileras de cuadros antiguos. Los muros revestidos de un discreto género verde armonizaban con los zócalos y molduras de madera. Con aquel paño resplandecían los marcos laminados en oro, encerrando mundos vastos y misteriosos que se abrían a épocas pasadas (Couve 102)

Esta preocupación por las condiciones materiales del espacio museal, junto a la labor de coleccionista, curador, crítico e historiador del arte, adviene por su conciencia de clase respecto de una manifestación cultural de tanto estatus como el arte plástico. No por la sapiencia o conocimiento estético respecto de lo coleccionado, porque el personaje sabe que son falsificaciones, por lo tanto, él también se encuentra falsificando una expresión disciplinaria tan específica como la labor curatorial. La reacción familiar y del eventual público o audiencia del museo pareciera seguir el final trazado por el "especialista" desde el momento en que "sus invitados solían acudir a aquella galería particular para dar las opiniones que sabe la burguesía sobre ella" (Couve 102)9. El nuevo estatus de los "dueños" del museo (Blanca y Sousa), entonces, desplaza el valor de las obras para centrarse en ellos. Dicho de otro modo, Blanca y Sousa se transforman en las obras exponibles, la verdadera colección no estaba en la pequeña galería de la pinacoteca particular implementada en Villacler, sino que son ellos dos las piezas artísticas valiosas y originales.

Sousa no es el único coleccionista dentro de la familia. Angelino y Blanca Diana también caen en el fuego del placer por la posesión (Pamuk), sin embargo, el verdadero acumulador de objetos ${ }^{10}$ será el esposo de la protagonista, puesto que, no solo es poseedor de objetos materiales.

\footnotetext{
${ }^{9}$ Algo semejante ocurre en La lección de pintura, novela de 1995, donde el boticario Carlos Aguiar se presenta como un gran entendido en arte, a partir de su gusto por la lectura de las biografías de genios pintores de la humanidad. Su saber, meramente enciclopédico, le basta para que todos los habitantes de la localidad donde vive, se reúnan en jornadas de conferencias alrededor de la vida y "obra" de algún gran nombre de la pintura. Nuevamente es el contexto alrededor del mundo del arte el que sanciona la sapiencia del sujeto, no el saber estrictamente disciplinario, sino su falaz conocimiento mediado por los dichos de otro, por la información general que es susceptible de ser encontrada en cualquier historia del arte.

${ }^{10}$ Antigüedad del Castillo-Olivares en "Coleccionismo, museos y mercado artístico, un debate actual” (2011) apunta: "El coleccionista, el amateur que busca y reúne con gran esfuerzo las más variadas piezas a través de ventas y subastas, experimenta un placer comparable al de los conquistadores que regresaban con el botín de
} 
Como ya hemos dicho, este sentimiento placentero e intemporal lo experimentan varios personajes de la nouvelle, provocando en algunos de ellos el deseo, e incluso la necesidad de querer poseerlo todo. Además, se repite la colección de objetos materiales e inmateriales falsos y sin valor intrínseco, como la imitación de algo o alguien, como sucede con el primer narrador del texto, personaje que no posee nombre. El adolescente que tiene su primera aparición en El picadero -al igual que la protagonista- es considerado un objeto de colección, no obstante, este no es un objeto artístico original, sino que una copia del hijo muerto de Blanca. El adolescente sin nombre tiene un gran parecido a Angelino, y la madre, ante este descubrimiento parece encontrar consuelo en la figura del jovencito. El púber sustituye a su hijo, incluso la protagonista no tiene dificultad de reconocerlo como tal: “Tenía mis ojos y mi frente, era de mi talla y cuando cabalgábamos, ella, en muchas ocasiones, se precipitaba sobre mis riendas para gritar: -¡Angelino, no sigas!” (Couve 62). La sustitución del original por una reproducción o por su valor atribuido sigue la lógica de la colección de materialidades, ahora con sujetos (o subjetividades) pareciera operar de la misma manera. Este primer personaje narrador es la imitación de Angelino, no solo por sus rasgos físicos, sino también por su entereza, gusto por la caballería y porque viene a reemplazar la ausencia del original proyectado en el jovencito muerto.

La protagonista buscó al adolescente para que le diera algunas lecciones de equitación, clases que al principio solo fueron una vez al mes pero que terminaron por ser todos los días, así pues, entre ellos el tiempo transcurría en ociosidades. El personaje sin nombre se convirtió en el objeto falso de la colección de la casona (museo), puesto que no era Angelino, sino que la imitación de él: “el maestro acariciándome con gran respeto agregó: -Se te parecía mucho. Eras casi él” (Couve 57). Entre estos dos personajes-objeto, tras la obsesión del uno hacia el otro, nace un amor incestuoso: "Amor que nunca se enfrentó con su propia realidad, situación que lo hizo perdurable. Quedó allí suelto ese sentimiento, cautivándonos a ambos" (Couve 58). La relación entre Blanca Diana y este personaje se limita a un amor idealizado, un sentimiento que abstrae el elemento sexual: "Si mis labios hicieron justicia a tanto desvelo e imprimieron en los suyos un beso, fue sólo en sueños. Sueño dentro de otro sueño, hijo dentro de otro ajeno, viejo amor dentro de uno 
nuevo" (Couve 58). No obstante, este tema tabú no será el único que se va a develar en la nouvelle.

Este amor hacia la copia de Angelino se comenzó a debilitar, en la medida que el jovencito se fue convirtiendo en hombre: “creo que logré dejar atrás la imagen de su hijo al crecer con mis años. Cuando esta situación fue a medias superada, tomó la costumbre de huir sin previo aviso" (Couve 62). Blanca Diana observó que con el pasar del tiempo el jovencito que sustituyó la imagen de su hijo muerto por varios años, ya no le era familiar. Recordemos que Angelino fallece a una corta edad, por ende, la madre tiene esa última imagen inmortalizada en sus recuerdos. El crecimiento de este personaje sustituto hace que la protagonista escape de la realidad y se aleje del joven, puesto que la réplica o la imitación del original se ha vuelto defectuosa. El paso del tiempo aleja la imagen del sustituto del original, por lo tanto, ya no puede ser parte de la colección porque no es copia de nada ni de nadie. Dicho cambio operado por el paso del tiempo provoca nuevamente el sentimiento de pérdida en la protagonista.

\section{Museo/mausoleo: receptáculo de pasiones humanas.}

La novela de Couve, tras las diferentes descripciones de escenarios, paisajes, la identidad de los personajes, las vestimentas y los espacios interiores, nos transporta en el tiempo a la sociedad chilena de fines del siglo XIX y comienzos del siglo XX donde el "progreso" alcanza un alto nivel de ingresos económicos gracia al capitalismo implantado y que posibilitó la generación de grandes riquezas, a la vez que exhibió una especie de matiz o modulación entre clases dominantes y dominadas. Ante este escenario buena parte de las familias burguesas fueron beneficiadas por el auge económico e industrial. En algún sentido es este el contexto general en que se mueve El picadero y sus inquietudes proyectadas en las páginas del texto, donde aparentemente el proyecto burgués está anclado en la falsificación y en la simulación instrumental de aquello que se encuentra en medio de una aparente coherencia y fastuosidad. 
La vida ostentosa de los Sousa nos hace reconocer a Angelino como un dandi ${ }^{11}$, un señorito de la época, un seductor elegante y presumido. Juan Pablo Sutherland en Cielo Dandi. Escrituras y poéticas de estilo en América Latina (2015) se refiere a lo expuesto de una manera clara y pertinente cuando señala: "Es interesante esta idea en la medida en que el dandi exhibe una diferencia, una alteridad estética, sexual, política, cultural" (Sutherland 7). Angelino, entonces, es el burgués que ejerce la distinción no solo por su vestimenta excéntrica sino también por su modo de ser, del que emana una compleja y sugestiva aura de elegancia y feminidad: "-Tienes el cuerpo de una jovencita, pero eres de fierro por dentro" (Couve 67). Este dandi latinoamericano será el encargado de hacer honor a la frase del narrador couveano cuando expresa: "El amor no necesitaba llamarse hombre o mujer" (Couve 67), serán Condarco y Angelino quienes exhibirán el desacato al "modelo masculino" cuando establecen una relación homosexual.

Condarco no pertenece a la familia Sousa ni a su clase, es el teniente de la escuela militar y la pareja homosexual de Angelino. El militar es un personaje que físicamente tiene mucha presencia "Cuando estuvieron frente a frente, observó Angelino a un joven de maligno aspecto, la nariz un tanto respingada y el rictus de la boca caído" (Couve 67), sin embargo, se nos exhibe como un ser inseguro que siempre necesita de la aprobación de Angelino, incluso a veces sin razón alguna pedía que este le perdonara, puesto que era el único que lo podía redimir. El problema de autoestima que vive Condarco lo satisface a través de sus diversas colecciones ¿Qué tipos de colecciones? La primera fue la “adquisición” de los muchachos gays que ingresaban a la escuela militar, mientras que su última posesión fue Angelino:

Acostumbrado a buscar de entre los cadetes nuevos a su presa, sabía leer en una nuca, en un ademán, todo un contenido. Hacía tanto tiempo que buscaba un ejemplar de éstos. Era tan fácil derribarlos. Admitir, en primer lugar, todo lo que tenían a favor: gusto, clase, cultura, todas aquellas dotes que se deben a una familia con prosapia (Couve 69)

Condarco tenía una colección de amores homosexuales, como bien dice el narrador, sabía diferenciar muy bien entre un heterosexual y un homosexual, y es Angelino quien se

\footnotetext{
11 "Distinción y elegancia fue lo ofrecido por el joven dandi que, emergiendo como un nuevo dios del buen gusto, levantará para sí mismo y los que lo siguieran, una muralla infranqueable e inaccesible para la burguesía en ascenso" (Sutherland 7).
} 
Artículo. Alexandra Novoa Romero, Juan D. Cid Hidalgo. "El museo-mausoleo: la búsqueda del placer a través de la colección de objetos artísticos en El picadero de Adolfo Couve"

convertirá en su siguiente objeto valioso, pues cumple con todos los requisitos para desearlo, para admirarlo, para poseerlo. "Hacía tanto tiempo que buscaba un ejemplar de éstos", tal y como lo hacen los coleccionistas que busca el objeto artístico, esa pieza única, "el coleccionista genuino es un apasionado que convierte su afición en un ritual que comienza por la búsqueda, por "la caza" del objeto deseado" (Navarro y Beltrán 287). ¿Pero qué sucede con Condarco cuando posee el objeto? Este personaje se queda absorto y se convierte rápidamente en un cuidador, en una especie de guardián, padre y hermano de Angelino ¿acaso no se comporta igual un coleccionista ante su objeto más preciado? Busca todos los cuidados para que la obra de arte no se estropee, pues la pieza es valiosa, es por ello que Condarco se vuelve obsesivo y sobreprotector con Angelino. En este sentido compartimos lo señalado por Navarro y Beltrán en Del coleccionismo privado a los museos. Una reflexión sobre la importancia del mecenazgo en tiempos turbulentos (2013), cuando reconoce esa cierta afinidad entre objeto coleccionable y sujeto coleccionista:

Cada objeto que conforma una colección es único, especial y, en la mayoría de las ocasiones, difícil de conseguir. Esto constituye una de las principales motivaciones del coleccionista, pues esa pieza en concreto puede ser clave, imprescindible para él, no por su valor económico -que puede tenerlo o no-, sino fundamentalmente por esa característica de unicidad, de pieza esencial, indispensable para poder continuar ese nuevo universo en el que la pieza pasará a integrarse (Navarro y Beltrán 287)

De este modo, Angelino se convierte en el universo de Condarco y pasa a ser parte de su colección. Este objeto artístico será para el teniente una felicidad pasajera mientras lo posee. La segunda colección de este personaje consta de: "pañuelos de seda de colores estridentes. Pañuelos que jamás mostró a su amigo" (Couve 71). Esta colección de algún modo busca ataviar a su poseedor ya que Condarco la utilizaba en las salidas nocturnas hacia los casinos ¿pero por qué se relaciona esta colección con el abandono de la escuela militar para visitar sitios de noche? ¿utilizaba estos pañuelos como parte de su identidad sexual? ¿travestismo? En el texto se informa al lector que Condarco era irreconocible y que tenía gustos extravagantes como poseer estos pañuelos de colores tan llamativos, tan fuera de su personalidad, dejando al margen a ese otro Condarco que se exhibía ante los cadetes y superiores. De esta forma el objeto coleccionado, en este caso los pañuelos, adquieren "el significado simbólico que le proporciona su nuevo propietario, que pasa a integrarlo en el 
“círculo mágico" de su micro-mundo, de su "caos ordenado", haciéndolo renacer" (Navarro y Beltrán 288).

Por otro lado, el personaje de Angelino en otro salto temporal y espacial de la nouvelle tendrá una relación heterosexual con Thérèse, una mujer que habitaba en París y que conoció cuando sus padres se separaron y Blanca, su madre, viajó a Francia. Nuestro personaje se siente ajeno y desea volver, fundamentalmente porque aún ama al teniente, no obstante, en París conoce a Thérèse e inicia una aventura amorosa que termina en un embarazo no deseado por Angelino, la solución era el aborto. De este modo, la huida perfecta del inconveniente embarazo de la parisina y el recuerdo de Condarco parecieran exigir el retorno a Villacler. Tanto así que el personaje declara pública y categóricamente cuando grita por el balcón: “Abrí las puertas de mi balcón que daban sobre el Palais Royal, y grité: -¡No soy feliz! ¡No soy feliz!” (Couve 90). Ante el vacío que le otorgaba el cielo gris de Paris, las calles frías y las comidas insípidas, el personaje inicia recorridos por anticuarios y galerías de artes, incluso la madre lo insta a tomar un curso de pintura en la Escuela de Bellas Artes, pero lo dejó al tiempo después porque reconoció no tener talento. Ese fue el único acercamiento que tuvo con el pincel, pero no así con el mundo del arte, puesto que ante las recurrentes visitas a galerías y exhibiciones, el muchacho se vuelve un coleccionista:

No conocía a nadie y el interés lo puse en las colecciones fabulosas del arte egipcio, griego y medieval que se exhibían en las vitrinas. Como me recibían de mala gana (...) mentí argumentando que yo era un sudamericano hijo de un coleccionista muy rico que buscaba para él, antigüedades con certificado. Así jugaba al gran señor con aquello entendidos (Couve 91-92)

Para Bernard Schulz-Cruz en "El claroscuro homosexual en El picadero, de Adolfo Couve" (2016) "el regreso del adolescente al país significa su autodestrucción; es decir, Chile pasa a ser el lugar donde la identidad homosexual de Angelino no puede materializarse" (Schulz-Cruz 166), sin embargo, creemos que frente al duro encuentro de Angelino con su historia pasada y deseada en Villacler, el personaje busca fortalecerse de algún modo para que su aceptación esté mediada por el prestigio de la actividad artística que, como sabemos en su caso, se sustenta en copias e imitaciones de obras de calidad, es 
decir, pura simulación. De hecho, el texto es terminante en el momento en que el muchacho declara "Cuando adivinaron que solo me movía el gusto por aquellas cosas, me aceptaron y enseñaron" (Couve 92). La imitación del gesto de Blanca Diana o del señor Sousa nos hace pensar que su forma de coleccionismo sigue esas mismas normas de calidad, donde lo verdaderamente importante es arrogarse un estatus social y cultural impostado y no el valor de las colecciones ${ }^{12}$. De algún modo con la legitimización de las obras y de su diferencia, Angelino busca también la legitimización de su diferencia sexual, sin embargo, esta posibilidad es inútilmente albergada por el personaje que será sometido a un ritual de expulsión del texto (Girard) mediante la violenta muerte del muchacho arrastrado por un corcel desbocado. La incorruptibilidad del cuerpo, cercana a la propuesta doctrinaria del catolicismo, pareciera otorgar, desde la perspectiva del narrador, una forma de reivindicación de Angelino, a pesar de la infracción mayor que significa ser homosexual en dictadura, en el contexto de una sociedad extremadamente conservadora y cruelmente normativa. En "El museo como representación de los conflictos sociales" (2011), Jaime Cerón, plantea que una idea que se articula productivamente con nuestra propuesta cuando señala que "el museo no solo involucra un proceso continuo de resignificación de los objetos, discursos e instituciones que conforman el campo del arte, sino que moviliza prácticas sociales, culturales y políticas que dan origen a procesos de inclusión y exclusión" (145). Efectivamente, a partir de una dinámica disciplinaria propia del universo del coleccionismo se desplaza la censura, el reparo ético y la discriminación en los personajes que, como dijimos, son piezas de una colección mayor, la colección de pasiones humanas.

El último personaje coleccionista sobre el que nos detendremos es el señor Sousa, el coleccionista de falsificaciones de arte, pero que, sin embargo, con el correr del texto, amplía su actividad desde coleccionar reproducciones a coleccionar otros "objetos artísticos": las amantes. Esta doble preocupación pareciera ir configurando también una doble vida: "el mundo que se atrevía exhibir y el otro clandestino" (Couve 47), ambas zonas en que proyecta el deseo de poseerlo todo. Al igual como sucede con la pinacoteca de su hogar, las amantes solo eran una imitación de la original Blanca Diana: "Ellas a su vez

\footnotetext{
12 Aurora León en El museo. Teoría, praxis y utopía (2010) apunta, a propósito de la relación del coleccionismo con la ideología, que "La masiva industrialización de la cultura (serigrafías, reproducciones, fotografías de arte, catálogos a "todo color"...) se presentan falazmente como medio de progreso cultural y de acceso a las masas cuando en realidad este progreso sigue afectando solamente a una clase burguesa que guisa, come y digiere a su antojo sus alimentos" (48).
} 
imitaban a Blanca, haciendo mofa de sus modales que en el fondo envidiaban" (Couve 48). Estas copias o imitaciones se regían del mismo modo que las colecciones de objetos, es decir, se debía invertir en ellas para mantenerlas, cuidarlas, vigilarlas y atenderlas, de tal manera que mantuvieran su prestancia y lozanía frente a sus eventuales espectadores. A pesar de ello, el señor Sousa estaba convencido de que ninguna de estas mujeres se hallaba a la altura del original, la protagonista: "Se lo llevaba comparando a Blanca con sus amantes, y tratando en vano de igualarlas" (Couve 48) ¿cómo lograr igualar la imitación con la original?

\section{Conclusión}

Como hemos podido constatar el acto de coleccionar es fundamental en el trabajo novelar de Adolfo Couve sobre el cual hemos reflexionado, sobre todo en la posibilidad de concebir los personajes como coleccionistas y/o como pieza de colección. Los primeros en tanto sujetos hedonistas en permanente búsqueda del placer de poseer, aun cuando, en el contexto de El picadero, sean obras burdas, copias o reproducciones. Y los segundos se nos exhiben como piezas de una colección de rarezas que Couve despliega, por cierto, en toda su producción narrativa. En este sentido creemos que el acto de coleccionar atraviesa la mera cuestión temática donde es evidente reconocer una especie de pinacoteca del señor Sousa y la casona como gran contenedor, sino que la misma nouvelle se monta como una especie de guion museal desde el momento en que los capítulos de la obra llevan el nombre de cada uno de los personajes: la primera parte: Blanca Diana, Zapiola y Condarco; y la segunda: Raquel, Angelino y el señor Sousa. De este modo se exhibe, se pone frente a los ojos mediante un dispositivo de visibilidad (la colección), el retrato de cada uno de ellos pintado con palabras, es decir, el libro es una galería de arte porque se exponen los retratospersonajes $^{13}$.

\footnotetext{
${ }^{13}$ El pensador e influyente filósofo francés, Jean-Luc Nancy, en La mirada sobre el retrato (2006), repara sobre algunos aspectos vinculados con el sujeto y su representación para concluir la imposibilidad de representación del sí mismo. Sin embargo, lo que nos interesa en este contexto de investigación es su reflexión sobre el retrato. El teórico francés apunta: "El retrato no consiste simplemente en revelar una identidad o un "yo". Esto es siempre, sin duda, lo que se busca: de ahí que la imitación tenga primeramente su fin en una revelación (en un develamiento que haría salir al yo del cuadro; o sea, en un "destelamiento" ...). Por esto sólo puede hacerse -si se puede, y este poder y esta posibilidad son lo que está precisamente en
} 
La exhibición, la galería, la colección, el museo, en que ha devenido la novela de Couve se ha convertido al final en un mausoleo, palabra que tiene el mismo tronco etimológico que museo (museion), pero que, sin embargo, enfatiza la idea de contenedor de muertos o de un monumento funerario que almacena sin más. En el epígrafe del ensayo "Sobre las ruinas del museo" (2005) de Douglas Crimp, recuerda un pasaje de Theodor Adorno en Prismas (1962), cuando plantea que el "Museo y mausoleo están relacionados por algo más que una proximidad fonética. Los museos son las tumbas de familia de las obras de arte" (Adorno 187). Esta condición mortuoria no solo se debe al evidente fallecimiento o sometimiento a rituales de expulsión de la mayoría de los personajes, sino también a que las colecciones, los objetos coleccionados son apenas baratijas que a pesar de estar acumuladas en un recinto sacralizador del arte mantiene su vulgaridad y no están afectos a puesta en valor. Ni los objetos ni los sujetos coleccionados en la novela asumen o cristalizan en alza su valor, aun cuando este pudiera ser meramente atribuido, es decir, esta galería de objetos artístico se ha convertido en un sepulcro.

Definitivamente los personajes de la obra literaria de Adolfo Couve coleccionan diversos objetos materiales e inmateriales para lograr sentir el placer intemporal que les produce adquirir nuevas piezas, en vista de que estas pequeñas olas de felicidad colaboren en hacer sus vidas menos tortuosas. La acción de coleccionar, entonces, se convierte en una obsesión, en una manía que podría proyectar un cambio sustantivo en los personajes, para quienes "la posesión del objeto soñado se desvanezca una vez que ha sido conseguido e, incluso, que no vuelvan a mirarlo nunca más. Les basta con saber que lo tienen ellos y no otros. Obsesión, neurosis, egoísmo, egocentrismo: coleccionismo" (Navarro y Beltrán 286). En palabras de Philipp Blom, en el texto citado, "coleccionar es llenar el vacío" (Blom 307), ese intersticio existencial que ronda permanentemente a los personajes de Adolfo Couve en El picadero. 


\section{REFERENCIAS}

Adorno, Theodor. "Museo Valéry Proust". Prismas. La crítica de la cultura y la sociedad. Ariel, 1962, pp.187-200.

Antigüedad del Castillo-Olivares, María Dolores. "Coleccionismo, museos y mercado artístico, un debate actual". Colecciones, expolio, museos y mercado artístico en España en los siglos XVIII y XIX, coordinación de María Dolores Antigüedad del Castillo-Olivares y Amaya Alzaga Ruiz. Centro de Estudios Ramón Areces, 2011.

Blom, Philipp. El coleccionista apasionado. Una historia intima. Anagrama, 2013.

Castilla, Américo. El museo en escena. Política y cultura en América Latina. Paidós, 2010.

Cerón, Jaime. "El museo como representación de los conflictos sociales". Calle14: Revista de investigación en el campo del arte, vol. 5, núm. 7, 2011, pp. 142-151.

Cid Hidalgo, Juan y Monserrat Grandón. Acerca de los espacios novelares marginales en La comedia del arte de Adolfo Couve". ALPHA: Revista de Artes, Letras y Filosofía, núm. 50, 2020, pp. 145-161.

Cid Hidalgo, Juan. "Larco: museo, memoria, déjà vu". Literatura: teoría, historia, crítica, vol. 21, núm. 1, 2019, pp. 225-252.

---. "Archivo y novela. Sobre la dimensión museal de la literatura latinoamericana". Literatura y Lingüistica, núm. 35, 2017, pp. 159-178.

---. "Museo, novela, archivo. Aproximación a los museos de papel”. Atenea, núm. 515, 2017, pp. 47-61.

Couve, Adolfo. Entrevista: Adolfo Couve. Una nueva Narrativa Chilena. Qué Pasa, núm. 1399, 31 de enero de 1998, pp. 80-82. Disponible en http://www.memoriachilena.gob.cl/602/w3-article-79761.html

---. Narrativa Completa. Editorial Planeta, 2003.

Crimp, Douglas. "Sobre las ruinas del museo". Posiciones críticas. Ensayos sobre las politicas de arte y la identidad. AKAL, 2005, pp. 61-72.

Debray, Regis. Introducción a la mediología. Paidós, 2001.

Desvallées, André y François Mairesse. Conceptos claves de museología. Armand Colin, 2010.

Foucault, Michael. Espacios otros: utopías y heterotopías. 1974. https://upcommons.upc.edu/bitstream/handle/2099/425/P005p.pdf

---. Vigilar y castigar: nacimiento de la prisión. Siglo XXI, 2004.

González Echevarría, Roberto. Mito y archivo. Una teoría de la narrativa latinoamericana. Fondo de Cultura Económica, 2000.

Maleuvre, Didier. Museum Memories: History, Technology, Art. Stanford University Press, 1999.

Nancy, Jean-Luc. La mirada sobre el retrato. Amorrortu, 2006.

Navarro, Artur y Clara Beltrán. "Del coleccionismo privado a los museos. Una reflexión sobre la importancia del mecenazgo en tiempos turbulentos". Goya: Revista de arte, núm. 345, 2013, pp. 285-303.

Nora, Pierre. Pierre Nora en les lieux de mémoire. Lom, 2009.

Reyes, Alfonso. Calendario. Cuadernos literarios, 1924.

Rozas, Daniel. "Claudia Campaña, amiga del pintor y escritor: 'En los 70, Adolfo Couve hizo una quema de sus óleos"”. La Segunda, 6 de octubre de 2017. 
Artículo. Alexandra Novoa Romero, Juan D. Cid Hidalgo. "El museo-mausoleo: la búsqueda del placer a través de la colección de objetos artísticos en El picadero de Adolfo Couve"

Schulz-Cruz, Bernard. "El claroscuro homosexual en El picadero, de Adolfo Couve". Revista Nomadias, núm. 21, 2016, pp. 155-173.

Sutherland, Juan Pablo. Cielo Dandi. Escrituras y poéticas de estilo en América Latina. Eterna Cadencia, 2015.

Toro, Franco. Una pieza secreta: juegos y juguetes en la narrativa de Adolfo Couve. Revista Chilena de Literatura, núm. 83, 2013, 177 - 195.

Valente, Ignacio. "El Picadero. Adolfo Couve". El Mercurio, 27 de octubre de 1974. 